\title{
THE TREATMENT OF HEMATEMESIS.
}

\author{
By CECIL A. JOLL, M.S., F.R.C.S. \\ (Senior Surgeon, Royal Free Hospital; Miller General Hospital; Surgeon, Royal Cancer \\ Hospital (Free).)
}

Few subjects in recent years can have aroused more controversy than the treatment of hæmatemesis and particularly that variety which complicates ulcerative lesions of the stomach and duodenum. There are, of course, many other causes for gastric hæmorrhage, e.g., lesions of the spleen and liver, thrombocytopœnia, etc. but as there is little difference of opinion as to the proper treatment of these, once they are recognized, I propose to confine my remarks to that form of hæmatemesis which is, or appears to be due essentially to local lesions in the stomach and duodenum. It must be admitted that even within this restricted field there is still scope for error since there are cases of bleeding, sometimes severe and frequently recurrent, without any demonstrable evidence of ulceration, acute or chronic, or of any neoplastic change in the gastro-duodenal tract. These cases of gastrostaxis usually occur without warning in patients lacking any of the characteristic symptoms pointing to gastric or duodenal ulceration, a feature which might be considered sufficient to render this class clearly differentiable, were it not that occasionally "silent" forms of gross ulceration occur with profuse hæmorrhage, particularly in the duodenum. It is possible that in gastrostaxis the bleeding comes from single, or more probably, multiple small erosions of the mucosa, but this is certainly not always true. Many surgeons in the past (including myself) before this class of case became better understood have been induced, not only to open the abdomen expecting to find a palpable ulcer, but on failing to do so have looked inside the stomach and duodenum without, however, finding the slightest trace of even superficial ulceration. Even in those cases where it is likely that acute superficial ulcers are the source of the hæmorrhage they have rarely been proved to exist, for few come to autopsy, and I do not know of any examined by modern gastroscopic methods soon enough after the bleeding to preclude the possibility that healing in the meantime had already occurred.

\section{FREQUENCY OF VARIOUS TYPES.}

There are wide divergencies of opinion on this matter. Thus Finsterer (1) claims that $98 \%$ of such cases are due to gastro-duodenal ulceration while Gutmann and Demole $^{(2)}$ put the figure below $20 \%$. Much must depend on the class of case likely to be attracted to the particular hospital or clinic from which the records are obtained. Bulmer's ${ }^{(3)}$ figures which relate to severe forms of hæmatemesis only, seem to me the most significant in connexion with the present article. In his series of 649 cases only 72 were due to causes other than gastric and duodenal ulcers.

\section{MORTALITY.}

Far more important than the discrepany in the figures just quoted is the difference of opinion as to the danger to life of hæmatemesis. Perhaps, as hinted above, the explanation of the figures is to be related to the different types of case which are attracted to various clinics as well as to the situation of the latter, since distance from thickly populated areas would reduce the number of admissions of gravely exsanguinated patients, while it would not necessarily militate against large numbers of gastric and duodenal lesions being admitted under less critical conditions. Even allowing for this possible explanation there is still an enormous 
gap between the highest and lowest figures given herewith, which relate to reports in which over 200 cases were observed:-

\begin{tabular}{|c|c|c|c|c|c|}
\hline & & & & \multicolumn{2}{|c|}{$\begin{array}{l}\text { Percentage } \\
\text { Mortality }\end{array}$} \\
\hline Davies and Nevin ${ }^{(4)}$ & $\ldots$ & (St. Thomas's) & $\ldots$ & $\ldots$ & $2 \mathrm{I}$ \\
\hline Hellier $^{(5)} \ldots$ & $\ldots$ & (Leeds) & $\cdots$ & $\ldots$ & 13 \\
\hline Aitken ${ }^{(6)}$ & $\cdots$ & (London Hospital) & $\ldots$ & $\ldots$ & II \\
\hline Bulmer ${ }^{(3)}$ & $\ldots$ & (Birmingham) & $\ldots$ & $\ldots$ & I0.7 \\
\hline Conybeare $^{(7)}$ & $\ldots$ & (Guy's) & $\ldots$ & $\ldots$ & 2.5 \\
\hline Meulengracht $^{18}{ }^{8} \ldots$ & $\ldots$ & (Copenhagen) & 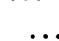 & .. & I \\
\hline
\end{tabular}

\section{INCIDENCE IN GASTRO-DUODENAL ULCERATION.}

There is fairly general agreement that the incidence of hæmatemesis in both gastric and duodenal ulceration is in the neighbourhood of $20 \%$ to $30 \%$, and in 3 gastro-jejunal and jejunal ulcers approximately $50 \%$, though in the latter cases $\vec{f}$ hæmorrhage is seldom of itself a grave matter. First hæmorrhages are only rarely fatal and the mortality rises appreciably with each recurrent attack.

\section{CLINICAL CLASSIFICATION IN RELATION TO TREATMENT.}

Group I. Hæmatemesis in peptic ulcer among patients who have been continuously under competent medical supervision. It is clear that, if in spite of medical treatment, bleeding is not prevented surgical treatment of the lesion is inevitable. This does not of course necessarily indicate that immediate operation is called for, since that matter cai only be determined in relation to the more general principles to by discussed subsequently.

Group II. Hæmatemesis occurring months or years after operation for peptic ulcer (this excludes immediate post-operative reactionary and secondary hæmorrhage) including operation for perforation and for hæmatemesis itself. In this group the presumption is that if hæmorrhage has occurred in spite of surgical treatment there is no good ground for further intervention. This would be true if in all cases one could be sure that the correct operative procedures had been adopted and as this is far from being generally true the decision as to further surgical measures will rest upon whether the ulcerating area had been radically extirpated or a mere short-circuiting operation carried out. If the former operation was performed then the hæmorrhage is seldom severe and never in my experience fatal so that it is usually safe to persist in medical treatment. If the latter operation was done, as the bleeding probably arises from the $\frac{7}{0}$ original ulcer then, after due investigation, the palliative short-circuit should be converted into the more radical extirpation-usually by of performing partial gastrectomy.

Group III. Hæmatemesis in patients with an extremely brief history of dyspepsia or with no history at all. Here the great risk that no demonstrable lesion will be found at operation, indicates the necessity for waiting until, under medical treatment, the patient is fit for a thorough radiological examination to determine whether any ulcer is present. The subsequent treatment is based on these findings. 
Group IV. Hæmatemesis in patients with a long history pointing to peptic ulcer but in whom there has been no continuous competent medical control. In this group and particularly in duodenal ulcer, there is always a reasonable hope of cure by medical means and therefore the case should be treated on its merits as revealed by repeated radiograms, etc. The only indication for urgent operation is uncontrolled hæmorrhage associated with rapid deterioration of the patient's general condition.

\section{CONSERVATIVE versus OPERATIVE TREATMENT.}

It is perhaps clear from the foregoing remarks that the writer cannot accept the views of such surgeons as Finsterer ${ }^{(1)}$ that hæmatemesis is ipso facto an indication for surgical treatment. According to this author the mortality of gastrectomy within 48 hours of the onset of the bleeding is $2.5 \%$, while for gastroenterostomy under like conditions it is $14.2 \%$. He contrasts these results with a mortality of $30 \%$ and $50 \%$ respectively if the operation is delayed to allow of preliminary medical treatment. These figures are so greatly at variance with the experience of those gastric surgeons throughout the world who have essayed routine early operative treatment that it would be folly to inculcate methods of therapy based on such views. On the other hand, the extremists who claim that urgent surgery is never necessary in hæmatemesis have gone too far in the other direction. According to such, hæmatemesis is very seldom fatal and, if it proves so, it is because the lesion is of such a character as to preclude a successful surgical intervention -in other words the patients who die without operation would also have died had the operative method been attempted. It is undoubtedly true that if anything effective is to be done for grave hæmatemesis by operative methods,. it is almost essential to extirpate the ulcer-bearing part of the stomach or duodenum as the case may be. Such an operation may tax the skill of the most experienced and intrepid gastric surgeon since not only is the ulcer usually large and fixed, but there is much œdema and fibrosis affecting the surrounding tissues, so that it is almost impossible to identify and open up those planes of cleavage necessary to effect a rapid and safe gastrectomy. Attempts to avoid such a major procedure by exclusion of the ulcer, cauterizing by Balfour's method, infolding of the ulcer, multiple ligation of gastric and gastro-duodenal arteries are seldom satisfactory and the less said about gastro-enterostomy as a method of treating hæmatemesis the better. Nevertheless, cases which would inevitably have proved fatal under medical treatment have undoubtedly been saved by operation. I quote an example which appears to me to belong to this class.

P. A. (male), at 54. Admitted to the Miller General Hospital, July 5, 1925 , immediately after a severe gastric hæmorrhage which had been preceded by many years of intermittent dyspepsia. His general condition was extremely bad; hæmoglobin 27 per cent. and his feeble pulse varied from 110 to 140 per minute. As this was before the systematization of continuous-drip blood transfusion he was given two separate blood transfusions, of 12 and 15 ozs. respectively, very slowly at intervals of some hours, combined with a slow rectal drip of 5 per cent. glucose saline. In spite of these measures which raised the hæmoglobin temporarily to 47 per cent. his general condition deteriorated and by the next day the hæmoglobin had fallen to 40 per cent. and the patient was semicomatose, his lips were dry, his tongue brown and shrivelled and my medical colleague urged me to intervene. Before I could reach the Hospital the patient's pulse became so bad that a further 15 ozs. of blood were given and my House Surgeon asked me to reconsider the advisability of operation as it did not appear to him possible to do 
anything without a fatality on the table. I was able, however, under local anæsthesia combined with a small amount of gas and oxygen, to carry out a partial gastrectomy for an ulcer $4 \mathrm{c}$ c.m. in diameter fixed to the pancreas in the base of which was the open artery responsible for the bleeding. I was able to control the hæmorrhage by an underrunning suture and the patient after a further blood transfusion of $20 \mathrm{ozs}$. in the theatre made a gradual recovery and was discharged within 28 days.

\section{INDICATIONS FOR IMMEDIATE SURGICAL TREATMENT.}

The case just described really illustrates in all essentials the main indication for urgent surgery which is as follows:-

Very severe hæmorrhage which persists in spite of absolute rest, morphine, starvation and judicious blood transfusions, bearing in mind that transfusion of too much blood or at an excessive rate is likely to cause recurrent hæmorrhage. In some cases the deterioration in the patient's condition is a better guide than the change in the actual hæmoglobin estimation. A rare indication is-perforation associated with severe hæmorrhage. In this case since perforation forces recourse to surgery the only question which is at issue concerns the necessary steps to deal with the bleeding as such. It is in this class of case only, that radical extirpation must be preferred to the simpler procedures usually indicated in perforation.

\section{MEDICAL TREATMENT.}

Medical treatment is indicated in all other cases so far as the immediate treate $\vec{\theta}$ ment of the hæmorrhage is concerned, though without prejudice to the desirabilit绐 of surgical intervention for the underlying lesion when the effects of the hæmorrhage. have passed off. These indications have already been sufficiently outlined under the four groups included in the clinical classification.

\section{PROPHYLACTIC TREATMENT.}

It is sufficiently obvious that adequate and consistent medical treatment so long as it is confined to cases in which there is a genuine prospect that the ulcer will heal completely, must provide a valuable method of avoiding hæmatemesis. The opinion is advanced by some surgeons that to avoid hæmatemesis it is necessary to adopt radical operative measures for all peptic ulcers, but it has been pointed out by Hurst ${ }^{\left({ }^{(9)}\right.}$ and by Gordon-Taylor ${ }^{(10)}$ that this contention is invalid because the mortality of such operations is greater than that of hæmatemesis itself. This does not, however, dispose of the view which I maintain, that by the proper choice of operation, in such ulcers as require it, the tendency to hæmatemesis is greatly reduced because the bleeding ulcer is removed, while the only forms of recurrent hæmorrhage to be feared after operation-that is from the anastomotic region itself-are never in my experience severe, much less fatal.

\section{THE MANAGEMENT OF SEVERE HEMATEMESIS.}

The following epitomizes the immediate treatment of severe hæmatemesis. The later treatment by appropriate medical or surgical measures directed to the stomach or duodenum or by the elimination of septic foci in the gallbladder, appendix or teeth need only be mentioned.

I. The patient should not be moved more than is necessary to make him comfortable. Transference to clinic or hospital need not be undertaken 
until a continuous-drip blood transfusion has been started. This can be continued during transport. If circumstances permit the blood is grouped, the hæmoglobin estimated, and suitable blood donors obtained from the relatives if available.

2. Morphine gr. $\frac{1}{4}-\frac{1}{3}$ is given hypodermically.

3. The continuous-drip blood transfusion is started as soon as possible and the flow is regulated at the slowest rate, care being taken to avoid clotting in the cannula. The details of the method have been described by Marriott and Kekwick ${ }^{(11)}$. Within a day or two, even in the more severe cases, the hæmoglobin often rises to 70 per cent. or more. Meanwhile the patient is starved except for sips of hot water or alternatively ice can be given so that the mouth can be washed out with cold water which must not be swallowed. I have no experience of the method of immediate feeding of these patients as advised by Meulengracht, nor do I think it rational.

If continuous-drip transfusion of blood is not possible small transfusions (IO-I5 Oz.) make a fair substitute, but they should be given slowly as there is undoubtedly a risk of stimulating further hæmorrhage unless transfusion is very gradually performed. Unfortunately the added blood does not appear to have any direct hæmostatic value. The various hæmostatic sera (hæmoplastin, etc.) are, in my experience, also valueless in hæmatemesis.

If blood is not available it is better to employ isotonic glucose solution ( $5 \%$ glucose in trebly distilled water) by the continuous-drip method, relving on the administration of large doses of a scale preparation of Iron (e.g. Ferri et Ammon Cit. gr. xxx t.d.s.) to raise the hæmoglobin content of the blood. Its effect is often remarkably rapid though, of course, not comparable with direct blood transfusion. I have a poor opinion of gum arabic or gum acacia as substitutes for blood transfusions and find them much inferior even to isotonic glucose solution.

4. If for any reason intravenous therapy is impossible a continuous-drip per rectum is a valuable substitute so long as it is recognized that the method requires careful supervision. I find that few trained nurses and not many house surgeons realize that to make this method a success the flow of saline from reservoir to rectum must be quite unchecked by valves or constrictions and it must be possible for any flatus which accumulates in the rectum to bubble freely out through the rectal tube and the saline in the reservoir. The latter should never be more than nine inches above the level of the anus-preferably an inch or two less. If these points are followed, up to twenty pints can be supplied in twenty-four hours without any loss alongside the tube.

5. Operation is called for when the above methods fail and the patient loses, rather than gains, ground. The operation is best done under cyclopropane and local anæsthesia, maintaining a blood-drip transfusion throughout the procedure. Partial gastrectomy or duodeno-pylorectomy should always be the operation of choice since it provides a direct attack upon the bleeding vessels, as well as offering the best chance of avoiding future hæmorrhages or future dyspepsia. In certain cases pyloroduodenoplasty will enable a bleeding ulcer to be attacked directly and 
the affected vessel to be ligated or underrun. In exceptionally difficult cases multiple ligation of gastric or gastro-duodenal vessels contiguous to the ulcerating area may be the only recourse but the value of this method is uncertain. Short circuiting operations should never be employed as they offer no reasonable hope of checking hæmatemesis.

\section{CONCLUSION.}

In the hands of specially skilled gastric surgeons capable of performing the necessary operative procedures quickly, there is undoubtedly a place for radical measures in dealing with those cases of hæmatemesis which will otherwise prove fatal if treated medically, but the most scrupulous weighing up of pros and cons is necessary before such operations should be undertaken.

\section{REFERENCES.}

(1) Finsterer, H., Traitement chirurgical de l'hémorragie profuse aiguë de l'estomac. Jour. de Chir. 1933.

xli1, 673-688.

(2) Gutmann, R. A. \& Demole, M. J., Bull. et Mem. Soc. méd. hôp. de Paris sur l'origine des hématémèses. 1932. Xlvili, $576-585$.

(3) Bulmer, E., Mortality from Hæmatemesis. Lancet. 1932. 11, 720-722.

(4) Davies L. \& Nevin, R., Prognosis of Hæmatemesis. B.M.J. 1934. 11, 858-859.

(5) Hellier, F. F., I2tiology \& Mortality Rate of Hæmatemesis. Lancet. 1934. 11, 1271-1274.

(6) Altken, R. S. The Treatment of Profuse Bleeding from the Stomach \& Duodenum. Lancet. 1934. 1. $839-842$.

(7) Conybeare, J. J., Discusston on Hæmatemesis. Proc. Roy. Soc. Med. 1934. 1563-1540.

(8) Meulengracht, E., Treatment of Hæmatemesis \& Melæna with Food. Lancet. 1935. 11, $1220-1222$

(9) Eurst, A. F. \&. Ryle, J. A., The Incidence, Mortality \& Treatment of Hæmorrhage in Gastric \& Duodenal olcer. Lancet. 1937 . 1, 1-6.

(10) Gordon-Taylor, G., The attitude of Surgery to Hæmatemesis. Lancet. 1935. 11. $811-815$.

(11) Marriott, H. L \& Kekwick, A., Administration of Fluids. Practitioner. 1937. cxxxix. 250-270. 